\title{
Production and assessment of polyclonal antibody against the whole virion of Goatpox virus and sheeppox virus in the rabbit
}

\section{Takele Tesgera Hurisa}

Lanzhou Veterinary Research Institute https://orcid.org/0000-0002-4365-2362

Huaijie Jia

Chinese Academy of Agricultural Sciences Lanzhou Institute of Husbandry and Pharmaceutical

Sciences

\section{Guohua Chen}

lanzhou veterinary research institute

\section{Fang Yong Xiang}

lanzhou veterinary research institute

\section{Xiao-Bing He}

lanzhou veterinary research institute

\section{Xia oxia Wang}

lanzhou veterinary research institute

Zhizhong Jing ( $\sim$ zhizhongj@163.com )

\section{Research article}

Keywords: Goatpox virus, Polyclonal antibody, Rabbit, Sheeppox virus, virion

Posted Date: August 14th, 2019

DOI: https://doi.org/10.21203/rs.2.12828/v1

License: (c) (i) This work is licensed under a Creative Commons Attribution 4.0 International License.

Read Full License 


\section{Abstract}

Abstract Background: Antibodies have emerged as essential tools of biomedical researches and are of great commercial and medical values. They are the fastest growing product segments of the pharmaceutical industry. Polyclonal antibodies are antibodies that secreted by different B cell lineages within the body. In this study production of polyclonal antibody against Goatpox and Sheeppox virion in rabbit was performed and subsequently; it will be used as the development of ELISA for detection of poxvirus in different species of animals. Results: After $0.5 \mathrm{mg} / \mathrm{ml}$ of the whole virion of the poxvirus was injected subcutaneously at multiple sites, the blood was collected at an interval of 14 days and antibody titration was conducted. GTPV A27 antigen was coated and indirect ELISA method was used for the titration of antibody then the mean of OD values for positive and negative results were analyzed by Microsoft excel window 7. The blood was collected and serum was prepared for IgG purification. The IgG was purified by Ammonium sulfate precipitation method which was dialyzed against 5lire PBS overnight at $+40 \mathrm{c}$. The protein concentration was determined spectrophotometrically at $280 \mathrm{~nm}$ wavelength and estimated as $2.29 \mu \mathrm{g} / \mu \mathrm{l}$ and $2.18 \mu \mathrm{g} / \mu \mathrm{l}$ against Goatpox virus and sheeppox virus respectively. Protein bands were checked by SDS PAGE and the molecular weights of $67 \mathrm{kDa}$ and $25 \mathrm{kD}$ as were estimated for IgG. similarly, antigen-antibody detection was checked by western blot. Conclusions: Based on the results of this study, the virion of Goatpox virus and Sheeppox virus is strong enough to produce antibody to develop ELISA kit for detection of poxviruses by coating GPTV A27 antigen. This study is the first to be conducted for the production of antibody from virions of Goatpox and sheeppox virus which was tittered by coating GTPV A27 antigen.

\section{Background}

Currently, purified antibodies have a fundamental role in the diagnosis and treatment of biological molecules. Considering the progress in biotechnology and production of recombinant drugs, the antibodies are used to separate and recognize manufactured products. Polyclonal antibodies are a set of diverse immunoglobulin molecules which produced against the specific antigen by different $B$ cell lineages within the body in which each of them is identifying, unlike epitope. Polyclonal B cell response is a natural mode of immune response exhibited by the adaptive immune system of mammals [1, 2]. Earlier studies revealed that immune response to poxvirus infection is very complex. Each arm of the immune system plays a crucial role in the separation and removal of poxvirus infection. Within a short period of time, enough humoral pox virus-specific antibodies can be developed and destroy the disease-causing virus. During removal of infection, antibodies use a variety of mechanisms such as virus neutralization and complement activation, opsonization and ADCC [3].In this study, the whole virion of Goatpox and sheeppox viruses were prepared and injected to the rabbits subcutaneously at multiple sites. The main aim of the current study is, to produce and compare antibody in the rabbit against the two kinds of poxviruses and subsequently to use for development of ELISA that will help to detect poxvirus infection in different species of animals. Accordingly, the whole virion of Goatpox virus and sheeppox virus was inactivated and adjuvated by complete Freud's adjuvant and injected to rabbits subcutaneously at 
multiple sites, later boosted using incomplete Freud's adjuvant. The blood was collected on 14 days interval, the serum antibody titration was determined by Indirect ELISA method and the mean of OD values of positive and Negative results were analyzed by Microsoft excel window 7. Antibody purification was conducted using ammonium sulfate precipitation technique which was dialyzed against 5 liter PBS overnight in $+4^{\circ} \mathrm{C}$ [4]. The purified antibody was quantified for protein concentration and evaluated by SDS PAGE electrophoresis and western blot [6].

\section{Results}

The main objectives of this research were to produce polyclonal antibody against virion of Goatpox virus and sheeppox virus in the rabbit and, after purification, to compare the antibody level between the two groups. later, it will be used for the development of ELISA which enables for detection of various poxviruses infection in different species of animals. In this study, the whole virion of the two poxviruses was prepared and immunized subcutaneously in multiple sites. Previous studies suggested that immunity to Sheeppox virus and Goatpox virus involves both humoral and cellular responses [7]. Antigens on the envelope and on the tubular elements of the virion surface stimulate protective antibodies. Beside cell-mediated immune response which eliminates the infection, antibodies prevent the spread of the infection within the body [8]. After $0.5 \mathrm{mg} / \mathrm{ml}$ of the whole virion of the virus with complete fraud adjuvant was inoculated subcutaneously at multiple sites, it was again boosted four times at an interval of two weeks with incomplete fraud adjuvant and the antibody titration was performed during each booster and the average of positive and negative OD values of rabbit with better antibody response was analyzed using Microsoft excel window 7(see fig.1 and 2). In both Goatpox virus and sheeppox viruses, antibody level was increased after 21 days. Finally, the whole blood was collected also antibody

purification was done by ammonium sulfate precipitation method. The concentration of purified antibody was estimated at $280 \mathrm{~nm}$ spectrophotometrically [4]. And the amount of IgG was determined as $2.29 \mu \mathrm{g} / \mu \mathrm{l}$ and $2.18 \mu \mathrm{g} / \mu \mathrm{l}$ against virion of Goatpox virus and sheeppox virus respectively. The purified Immunoglobulin $\mathrm{G}$ was analyzed by SDS PAGE with Page Ruler ${ }^{\mathrm{TM}}$ Prestained Protein Ladder part No26616, 26617 standard molecular protein markers (see Fig. 3 for virion of Goatpox virus and Fig. 4 for virion of Sheeppox virus). Different bands were visualized clearly in the purified antibody and the molecular weight of $\mathrm{IgG}$ was estimated as $67 \mathrm{KDa}$ and $25 \mathrm{KDa}$, for both Goatpox virus and Sheeppox virus. Since the next work is to develop ELISA for detection of different poxviruses after coating of GTPV A27 antigen, antibody/antigen binding was confirmed by western blot and observed at 35kDa which is the molecular weight of GTPV A27 that was expressed and purified in our laboratory earlier (see Fig. 5).

\section{Discussion}

In biomedical researches, antibodies are emerging as fundamental tools and they have great commercial and medical values. Also, antibodies are considered as the fastest growing product sector of the pharmaceutical industry. Therapeutic antibodies are significant drugs for the treatment of autoimmune diseases and infections. Furthermore, antibodies are important substances in diagnostic and medical 
researches including therapeutic effects $[9,10]$ they are a combination of monoclonal Abs produced against different epitopes of antigens and have great avidity to polyvalent antigens [11, 12]. Sheeppox virus, Goatpox viruses, and Lumpy skin disease viruses are surprisingly alike to one another, sharing $97 \%$ nucleotide identity and studies also revealed that Sheeppox virus and Goatpox viruses share about $96 \%$ nucleotide identity over their entire length [13]. Taking into consideration of the genomic resemblance of Capripoxviruses, we coated GTPV A27 antigen to determine the antibody titration against virion of Goatpox and Sheeppox viruses in the rabbit and we observed almost similarities in positive and negative OD values in both groups which indicate sharing of alike genes[see Fig 1 and 2]. Even though there could be various techniques available for quantification of protein, like BCA and brand fold techniques, here in this research, the antibody was purified by ammonium sulfate precipitation method in which protein concentration was estimated spectrophotometrically at $280 \mathrm{~nm}$.Previous studies illustrated that Capripoxvirus has five major structural proteins. According to Chand et al. [14] description about the major proteins including polypeptides of different molecular weight of capripoxvirus, the 67kDa and $32 \mathrm{kD}$ as are located on the envelope of the virus having dissimilar functions in which the former has the ability to precipitate the antigen like the $45 \mathrm{kDa}$ protein and contains cross-reactive antigenic determinants [17]. The $32 \mathrm{kD}$ a protein contains epitopes that induce neutralizing antibodies signifying that the protein is strongly immunogenic in nature [16]. Chand et al.also mentioned the properties of a $26 \mathrm{kDa}$ and $19 \mathrm{kDa}$ proteins situated in the core of the virion of Capripoxvirus where the $26 \mathrm{kDa}$ has the ability to induce neutralizing antibodies. In this current research, we detected $67 \mathrm{kDa}$ and $25 \mathrm{kDa}$ for IgG of both Goatpox virus and Sheeppox virus and the other bands observed could be either peptide separated from IgG or other serum proteins (Fig.3 and Fig 4).

\section{Conclusions}

After immunization, the development of an antibody against virion of Goatpox virus and Sheeppox viruses' was observed in rabbit which determined by the coating of GPVA27 protein for titration. The result revealed that both pox viruses virion have the ability to provoke antibody and also indicated the cross-reactivity of the two viruses, hence, the antibody can be used for the development of ELISA kit for detection of poxvirus infection in animals. This study is the first to be conducted for the production of antibody from virions of Goatpox and sheeppox virus which was titered after coating of GTPV A27 antigen.

\section{Methods}

\section{Production of polyclonal antibodies}

Animals used: Six, three for each group genetically approved New Zealand female white rabbits were purchased from Lanzhou veterinary research institute laboratory animal breeding section and immunized subcutaneously at multiple sites with $2 \mathrm{ml}$ of inactivated Goatpox virus and Sheeppox virus containing $0.5 \mathrm{mg} / \mathrm{ml}$ of the whole virion of the virus with complete Freud's adjuvant (Sigma, ALDRICH, USA, Lot No SLBV6904) and they were later boosted every two weeks with the same preparation of Freud's incomplete 
adjuvant. Before each immunization, blood was drawn by venous puncture from the rabbit marginal ear vein and allowed to clot for 2 to $3 \mathrm{hrs}$ at room temperature prior to preparation of sera. Titration of the specific polyclonal antibody was then performed 1-10 days after each booster. Indirect ELISA method was used for titration of antibody during the trial and after the titer was determined, the whole blood was collected and the rabbits were killed by applying cervical dislocation. Finally, a rabbit with better antibody titer was selected from each group (virion of Goatpox and Sheeppox virus immunized) and the mean OD values of the result were analyzed by Microsoft excel window 7 and at the same time, antibody purification was conducted using ammonium sulfate precipitation method [4].And confirmed by SDS PAGE as well as western blot. Preimmune withdrawn blood was used as a negative control. No local reaction or any abnormalities were observed at the site of injection during the test.

\section{Declarations}

\section{Ethics statement}

The rabbits used during the experiment were registered and approved by the responsible governmental authorities (Office for Health and Social Affairs in Lanzhou veterinary research institute; Licence number SYK2015-0003) and were housed according to national regulations. The physical conditions of the animals were monitored daily. The animals were supplied with feed and enough water. No animal was ill or died at any time during the undertaking of the experiment. Blood from Rabbit was collected safely. Every endeavor was made to minimize pain and distress during the production of polyclonal antibodies following established best practices [5].

\section{Determination of antibody titration}

After serum was isolated from the whole blood, the indirect ELISA technique was used for antibody titration. The microplates were coated with GTPV A27 antigen at a concentration of $2.5 \mu \mathrm{g} / \mathrm{ml}$ in coating buffer $(100 \mu \mathrm{l} /$ well), which was purified and optimized for coating in our laboratory for the development of ELISA and incubated at $+4^{\circ} \mathrm{C}$ overnight. Plates were washed by PBST three times to remove unbound antigen and then treated with $5 \%$ skimmed milk powder in PBS $(150 \mu \mathrm{l} /$ well), followed by incubation for $2 \mathrm{hrs}$ at $37^{\circ} \mathrm{C}$ to block the nonspecific reactions. Again after washing three times, the appropriate dilution of the antisera (collected from GTPV and SPV immunized rabbits) was added and, the plates were

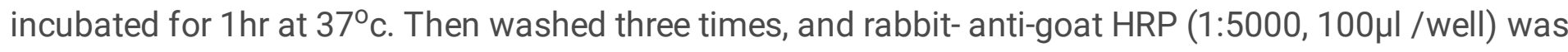
added, followed by incubation for $1 \mathrm{hr}$ at $37^{\circ} \mathrm{C}$. Plates were washed again as above and $100 \mu \mathrm{l} /$ well of TMB substrate solution was added and incubated for 15 minute at $37^{\circ} \mathrm{C}$. The enzymatic reaction was stopped with sulfuric acid $(2 \mathrm{M}, 50 \mu \mathrm{l} /$ well $)$ and the yellow plate was spectrophotometrically read in a single wavelength mode at $450 \mathrm{~nm}$. Preimmune withdrawn serum was used as a negative control and, the antibody titer was defined as the reciprocal of the dilution resulted in an absorbance value which was twice that of the background (see fig.1 and 2). 
Ammonium Sulfate Precipitation method was used for IgG purification. Rabbit serum was diluted in the proportion of $1: 2$ with PBS in ice, the prepared $45 \%(\mathrm{v} / \mathrm{v})$ saturated ammonium sulfate was added into final concentration in a dropping manner, the mixture was stirred at $+4^{\circ} \mathrm{C}$ for 30 minutes and centrifuged at $1000 * \mathrm{~g}$ for 15 minutes at $+4^{\circ} \mathrm{C}$. The precipitate was collected and washed with $45 \%$ saturated ammonium sulfate and centrifuged again at $1000 * \mathrm{~g}$ for 15 minutes at $+4^{\circ} \mathrm{C}$, then redissolved in the same volume of PBS as the original antibody solution and centrifuged again at $5000 * \mathrm{~g}$ for $15 \mathrm{~min}$ at $+4^{\circ}{ }_{\mathrm{C}}$ to remove any insoluble material. Subsequently, the supernatant was transferred to clean tubes and the immunoglobulin was reprecipitated by using $40 \%$ saturated ammonium sulfate and the centrifugation was repeated at $1000 * \mathrm{~g}$ for 15 minutes at $+4^{\circ} \mathrm{C}$. The precipitate was again redissolved in the $5 \mathrm{ml}$ volume of PBS and dialyzed against 5 liter PBS at $+4^{\circ} \mathrm{C}$ overnight to remove the trace of ammonium ions, to prevent interference of subsequent procedures like conjugation of antibodies with biotin and fluorochromes or agarose and centrifuged at $5000 * \mathrm{~g}$ for 15 minutes at $+4^{\circ} \mathrm{C}$ to get rid of more insoluble substances. Finally, the supernatants were collected and an aliquot was sampled for SDS PAGE (Fig.3 and Fig.4), and the rest was stored at $-70^{\circ} \mathrm{c}$ [4].

\section{Western blot}

In this study, besides polyclonal antibody production, a $35 \mathrm{kDa}$ GTPV A27 protein was expressed and purified in our laboratory which was used for titration of the serum and again will be coated and intended for the development of ELISA. The protein band obtained by SDS-PAGE was transferred to nitrocellulose membrane and then probed by its corresponding antigen/antibody (See fig 5). Western blot or immune blot was employed to detect the target protein and the target protein was verified in the sample antigen [4].

\section{Abbreviations}

$\mu \mathrm{g}:$ microgram; $\mu l:$ microliter; Abs: Antibodies; ADCC: Antibody-dependent cytotoxic cells; BCA:

Bicinchoninic acid assay; ELISA: Enzyme-linked immunosorbent assay; g: gravity; GTPV: Goat pox virus; Hr: hour; HRP: Horse reddish peroxides; IgE: Immunoglobulin E; IgG: Immunoglobulin G; KDa: Kilo Delta; LSDV: Lumpy skin disease virus; mg: milligram; ml: milliliter; M: Mole; M: Molecular marker; nm: nanometer; ${ }^{0}$ : degree Celsius; OD: Optical density; Orf: Sore mouth infection; PAs: Polyclonal antibody; PBS: Phosphate buffer saline; SDS PAGE: sodium dodecyl sulfate-polyacrylamide gel electrophoresis; SPV: Sheeppox virus; TMB: Tetramethylbenzidine.

\section{Ethics statement}

All animal experiments followed the regulations of the Institutional Animal Care and Use Committee of Lanzhou veterinary research institute (Licence number SYK2015-0003). 


\section{Statistical analysis}

Microsoft Excel Window 7 was performed for statistical analysis. GTPV A27 antigen was coated and indirect ELISA method was used for the titration of antibody then the mean of OD values for positive and negative results were analyzed.

Declarations

\section{Ethics approval and consent to participate}

Animals were purchased from Lanzhou veterinary research institute laboratory animal breeding section. All animal experiments followed the regulations of the Institutional Animal Care and Use Committee. The animals were registered and approved by the responsible governmental authorities (Office for Health and Social Affairs in Lanzhou veterinary research institute Licence number SYK2015-0003).

\section{Consent to publish}

Not applicable.

\section{Availability of data and materials}

The data regarding antibody titer against the whole virion of Goatpox and Sheeppox virus in the rabbit is found at the link below.

\section{Mean OD value.docx}

\section{Competing interests}

The authors declare that they have no competing interests.

\section{Funding}

This work was supported by the 13th Five-year Plan National Science and Technology Support program (Grant number 2017YFD 0500903) State Key Laboratory of Veterinary Etiological Biology, Key Laboratory of Veterinary Public Health of Agriculture Ministry, Lanzhou Veterinary Research Institute, Chinese Academy of Agricultural Sciences. Funding bodies had no roles in the design of the study and collection, analysis, and interpretation of data and in writing the manuscript. 
ZJ and TT designed the study, TT performed the experiment, TT wrote the manuscript, ZJ edited the manuscript, GC supplied GTPV A27 protein, HJ, FX, XH and XW were contributed to the overall support of this study. All authors read and approved the final manuscript.

\section{Acknowledgments}

We like to thank the National Science and Technology Support program of China for funding us during this work and also we would like to extend our appreciation to Dr. Guohua Chen for kindly supplying us cloned GTPV A27 protein from Lanzhou veterinary research institute department of livestock and poultry zoonosis, China and for her technical assistance.

Authors Information

Authors.docx

\section{References}

1. Stavitsky AB, Jarchow CC (1954): Procedure and general applications of hemagglutination and hemagglutination-inhibition reactions with tannic acid and protein-treated red blood cells. $J$ Immunol.72:360-7.

2. Kno"r S, Khrenov AV, Laufer B, Saenko EL, Hauser CA, Kessler H(2011): Development of a peptidomimetic ligand for efficient isolation Ind J Clin Biochem 26(4):354-359.

3. Kotwal G.J., (1997): Microorganisms and their interaction with the immune system, J. Leukoc. Biol., 62 : 415-29, Infection with Orf virus, Vet. Immunol. Immunopathol., (1989) 22: 321-32.

4. Harlow E and Lane D (1988): Antibodies: A Laboratory Manual. Cold Spring Harbor, NY, USA: Cold Spring Harbor Laboratory Press.

5. Carstens E, Moberg GP (2000): Recognizing pain and distress in laboratory animals. ILAR J.41 (2):6271. PMID: 11304586.

6. Goetz DW (2005): Cross-reactivity among edible nuts; double immunodiffusion, crossed immunoelectrophoresis and human-specific IgE serologic surveys. Ann Allergy Asthma Immunol 95:4552.

7. Kalra, S. K. and Sharma V. K. (1984): Cell-mediated and humoral immune response of sheep to attenuated sheeppox virus. Indian Journal of Animal Science, 54: 450-456 
8. Penkova, V.M., Jassim, F.A., Thompson, J.R. and Aldoori, T.M. (1974): Bull. De. Office, Inter.Des. Epizoo., 81: 329 .

9. Aghebati-Maleki L, Majidi J, Baradaran B, et al. (2013): Large scale generation and characterization of anti-Human CD34 monoclonal antibody in ascitic fluid of Balb/c mice. Adv Pharm Bull.3 (1):211-216. [ PMC free article] [ PubMed].

10. El Bakri A, Nelson PN, Odeh ROA (2010): The state of antibody therapy. Hum Immunol. 71(12):12431250. [ PubMed].

11. Maleki LA, Majidi J, Baradaran B, et al. (2013): Production and characterization of the murine monoclonal antibody against the synthetic peptide of CD34. Hum Antibodies. 22(1-2):1-8. [ PubMed].

12. Lipman NS, Jackson LR, Trudel LJ, et al (2005): Monoclonal versus polyclonal antibodies Distinguishing characteristics, applications, and information resources. ILAR J.46 (3):258-268. [ PubMed].

13.Tulman ER, Afonso CL, Lu Z, Zsak L, Sur J H, Sandyabaev N T, Kerembekova U Z, Zaitsev V L, Kutish G F and Rock D L (2002): The Genomes of Sheep pox and Goat Poxviruses. J Virol 7:6054.

14. Chand P, Kitching R P and Black D N (1994): Evaluation of the Western blot analysis of virus-specific antibody responses to capripox and contagious pustular dermatitis infections in sheep Epidemiol Infect 113:377-385.

15. Kitching, R. P., Hammond, J. M. and Black, D. N. (1986): Studies on the major common Precipitating antigen of capripox. Journal of General Virology 67:139-148.

16. Maa, J. S., Rodriguez, J. F., and Esteban, M. (1990): Structural and functional characterization of a cell surface binding protein of vaccinia virus. The Journal Biological Chemistry 265:1569-1577.

17. Woodroofe, G. M, and Fenner, F. (1962): Serological relationships within the poxvirus group an antigen common to all members of the group. Virology 16:334-341.

\section{Figures}




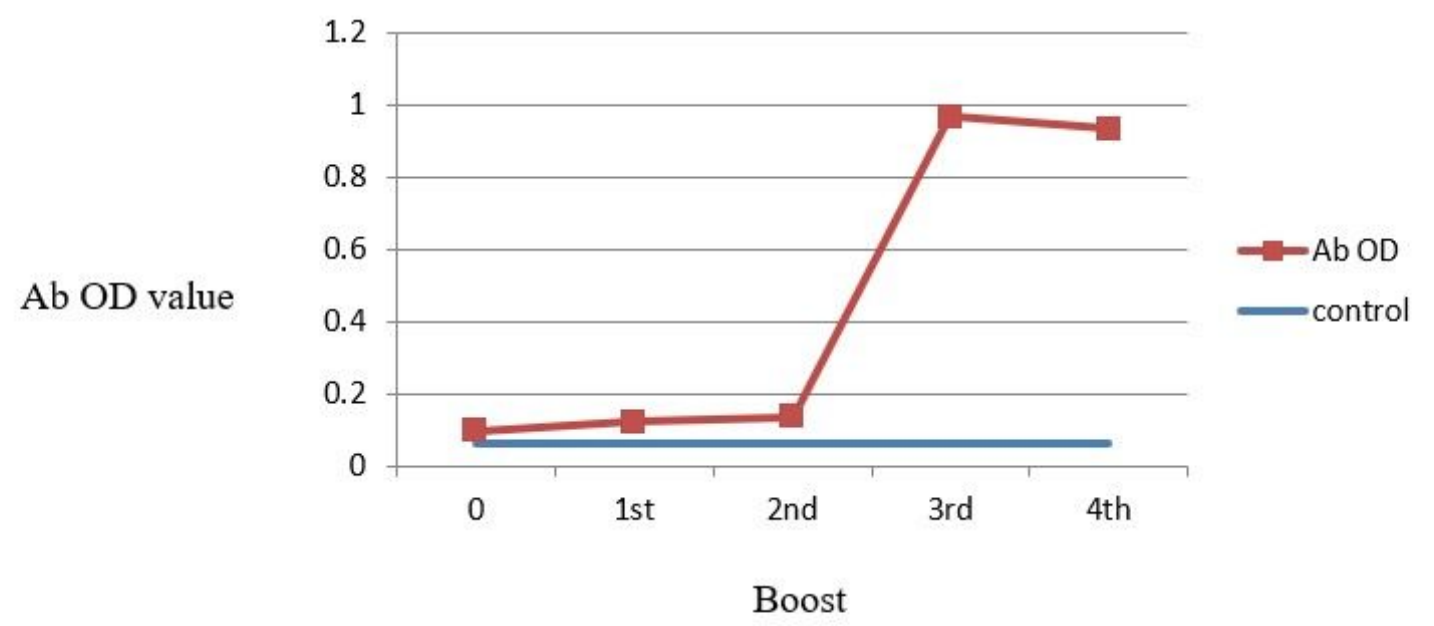

\section{Figure 1}

Antibody titer against virion of Goatpox virus. The figure shows that, in the first boost of antigen, the serum antibody titration was almost similar to that of the negative control and following the second boost it was increased exponentially, later after third and fourth boosters, antibody titration was continued in slight decline.

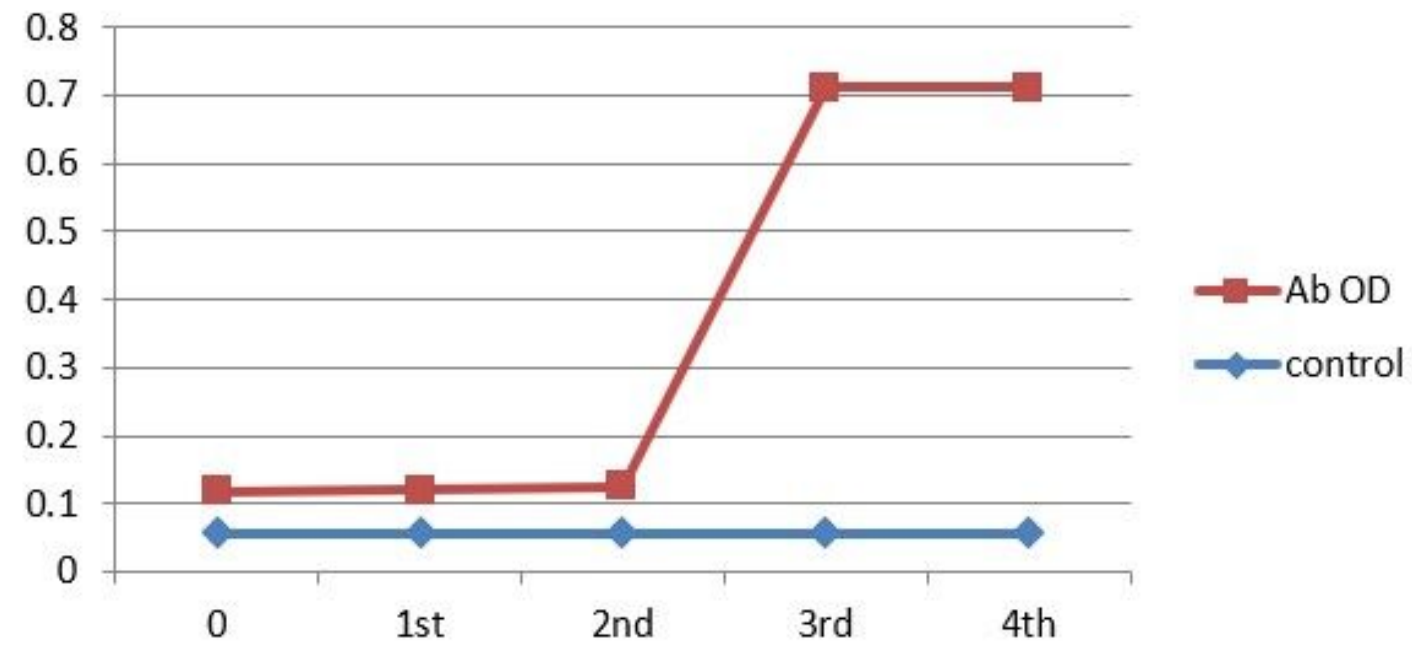

Boost 
Figure 2

Antibody titer against virion of Sheeppox virus. The figure reveals that, in the first boost of antigen, the serum antibody titration was almost similar to that of the negative control and after the second boost the level of antibody increased, later posts third and fourth boosters, the antibody titration was continued constantly.

\section{Mark. GTPV}

\section{A}

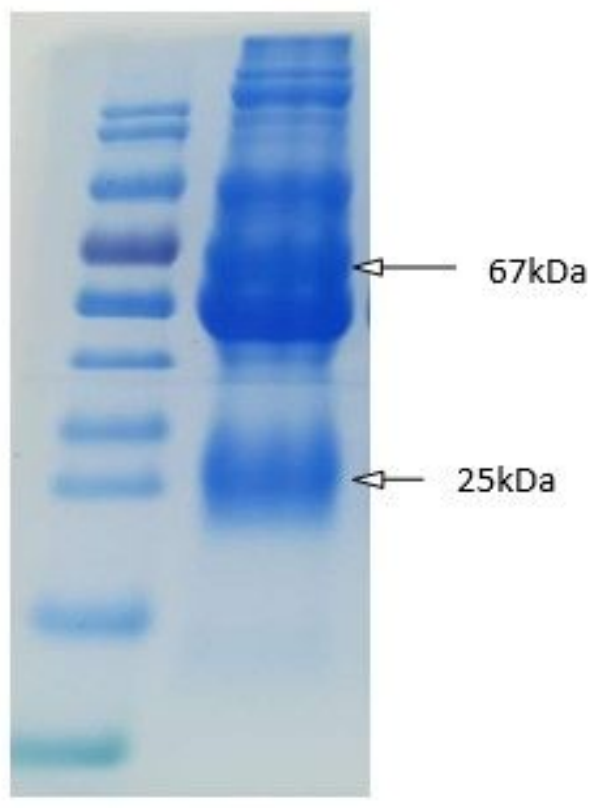

\section{Figure 3}

SDS PAGE analysis of rabbit IgG against the whole virion of Goatpox virus (A) 


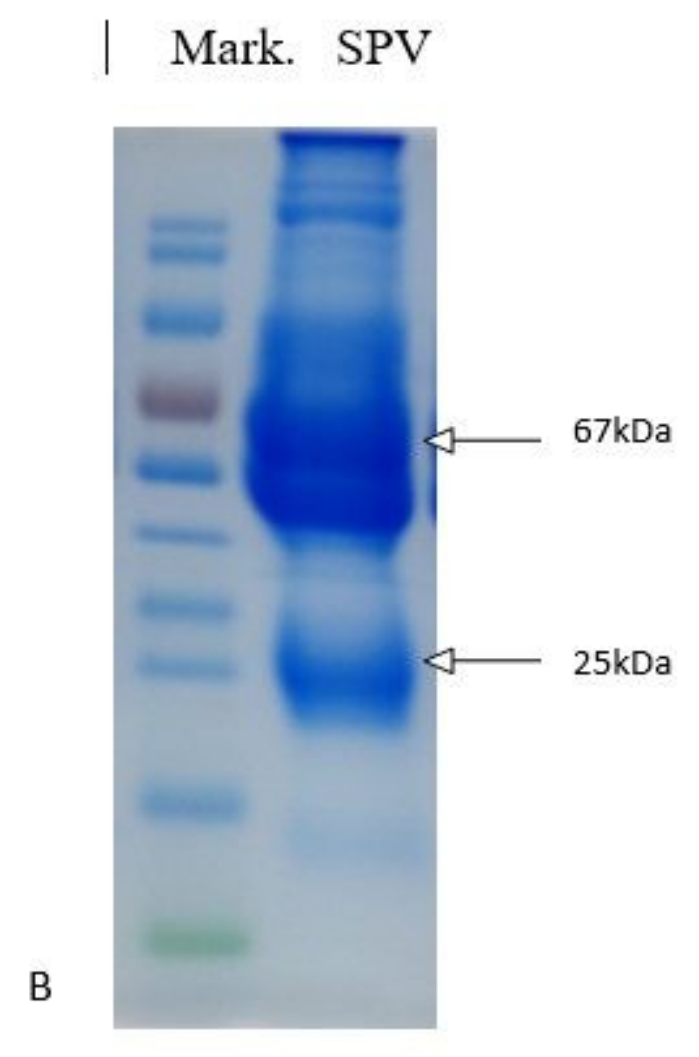

Figure 4

SDS PAGE analysis of rabbit IgG against the whole virion of Sheeppox virus (B) 


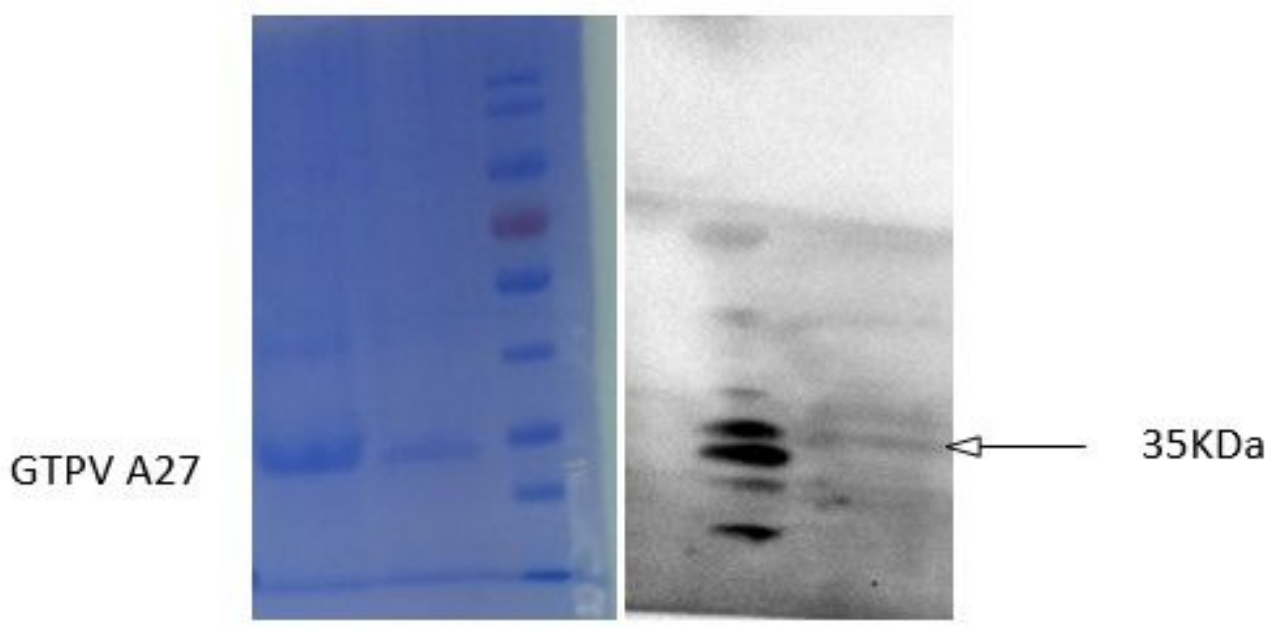

Figure 5

The antigen/antibody binding was checked by Western blot. A distinguished band was observed at $35 \mathrm{KDa}$, which is the molecular weight of GPV A27 that was expressed protein in our laboratory.

\section{Supplementary Files}

This is a list of supplementary files associated with this preprint. Click to download.

- Arriveguidelines.docx 